\title{
No Longer Sojourners: The Complexities of Racial Ethnic Identity, Gender, and Generational Outcomes for Sub-Saharan Africans in the USA
}

\author{
Natasha M. Rivers \\ Center for Studies of Demography and Ecology (CSDE), The University of Washington, Seattle, WA 98195, USA \\ Correspondence should be addressed to Natasha M. Rivers, nmrivers@gmail.com
}

Received 29 November 2011; Accepted 5 March 2012

Academic Editor: Eric Fong

Copyright () 2012 Natasha M. Rivers. This is an open access article distributed under the Creative Commons Attribution License, which permits unrestricted use, distribution, and reproduction in any medium, provided the original work is properly cited.

\begin{abstract}
Through individual and group testimonies from newly arrived, 1.5 and second generation sub-Saharan Africans (For this study sub-Saharan African refers to the countries located under Northern African countries, for example, Egypt and Morocco and, includes South Africa. There are over 50 countries represented by this region; however, the most populous groups from this region in Africa in the USA are Nigerian, Ethiopian, Kenyan, Liberian, Ghanaian, Cape Verdean, South African, and Somalian.), the diversity and complexity linked to their migration and integration experiences in the USA reveal that there is a gendered and generational element to their self identity. These elements are compounded by perceptions of being African American in a racialized society and deciding whether or not to stay connected to Africa, a continent that needs their financial, political, and social resources accumulated in the USA These "new" African Americans expand the definition of blackness in the USA. Many have created a transnational relationship to Africa and the USA, which provides important implications for Africa's potential "brain gain" as well as socioeconomic, infrastructural, and political development.
\end{abstract}

\section{Introduction}

International migration flows from Africa to the United States have been steadily increasing since the 1980s, with noticeable gains after 1990 [1-3]. Terrazas [1] states "The number of African immigrants in the United States grew 40fold between 1960 and 2007, from 35,355 to 1.4 million. Most of this growth has taken place since 1990." As newly arriving Africans add to the growing foreign-born and Americanborn African populations in the USA, it is important to note that, first, the moves and settlement are more permanent today than in previous decades, and second, there are important gender, racial, and generational outcomes that impact how these groups relate to both continents over time in particular ways. Research suggests one essential way is that migrants are sending financial capital back to African nations [4-6]. Another recent trend shows that transnational relationships develop for the older migrants, but that the more recent African descendents, 1.5 and second generation, prefer to stay in the USA This outcome is related to integration and assimilation experiences.
Research conducted on newly arriving African immigrant groups and their adjustment and integration in the USA is both urgent and necessary. As the number of sub-Saharan Africans increases in the USA, and becomes semipermanent or permanent residents, there will be an increase in American-born African children. These children are socialised in school systems in USA. How subSaharan African children acculturate and are accepted at their schools and by their peers may influence how they identify themselves and perform in education and later in life. Assessing current literature on the integration of 1.5 and 2nd generation blacks from the Caribbean sheds light on the similarities and differences for those arriving from subSaharan Africa, and the younger generations growing up in the USA.

This study uses the findings from 24 structured interviews and focus group session of six participants to explore racial ethnic identity, the role of gender, and generational outcomes with newly arriving sub-Saharan African immigrants, 1.5 and 2nd generation participants, 
to (a) explore the complexities of racial ethnic identity formation, (b) to assess generational outcomes as they pertain to the sub-Saharan African population in the USA, and (c) to evaluate the role of gender in terms of education outcomes and integration. The sub-Saharan African immigrant countries represented in this study are from Nigerian, Ethiopia, Kenya, Liberia, Ghana, The Democratic Republic of Congo, and Somalia. The most populous groups in this sample were from Nigeria and Ethiopia; this result is also comparable to national data. The top five countries of origin for African countries are from Nigeria, Egypt, and Ethiopia with Nigerians making up the largest percent at 13.1 percent [1]. Previous research confirms there are many African immigrants coming with and obtaining college degrees in the USA. However, not all African immigrants are coming with higher education nor the pursuit of it. After the 1990 Immigration Law, also responsible for enacting the Diversity Visa lottery, there has been a bifurcated flow of skilled and unskilled immigrants and refugees from Africa. Those sampled in this study were highly educated and for many their race did not hinder their education attainment, but ethnicity may have been a factor in how much education they were choosing to obtain. For example, certain cultural attributes of ethnic groups in Africa pushed education in the origin country and even more so in the USA Some respondents felt African Americans did not take advantage of the "free" education offered in American schools, and for the respondents unaware of the history of the African American experience in terms of access to institutions of education and employment made generalizations about this racial group and in turn felt they needed to distance themselves from the negative stereotypes that remain till today. In this study I will also assess how sub-Saharan Africans find community (ethnic or racial) and interact with other black groups (foreign born and native born) in the USA.

In my findings, newly arriving sub-Saharan African immigrants and refugees identify more with their country of origin and ethnic group than with African Americans, many are high achievers and highly motivated, many want to contribute their skills and education received in the USA to rebuild Africa and make it a highly functioning continent. Most respondents prefer to maintain relations to Africa but also keep the option of making a life for themselves in the USA. African women seem to be entering higher education at higher rates than their male counterparts, and both male and female respondents commented on this perception and emerging reality. Before examining the results of my focus groups, I review current understandings of racial-ethnic identity, academic performance, and adjustment and integration of recent Caribbean and African immigrants. This study is significant because it provides a snapshot, small sample made up of sub-Saharan African populations in Los Angeles County and Seattle, Washington, of what this population deals with in terms of family life, adjustment in the USA, and the formation of a racial-ethnic identity sometimes unknowingly placed upon them.

\section{Literature Review and Theoretical Section}

2.1. African Identities and Performance. Is performance in areas of education and employment linked to racial and ethnic identity formation in the USA? For the purposes of this study, performance and identity serve a dual role. Performance refers to the individual's conceptualization of his/her identity and the impacts, positive or negative, that this identity has on education attainment and income outcomes and success in those areas. This analysis is organised around three research questions: what impact does African American performance in areas of education and employment has for the development of sub-Saharan African group identity in the USA over time? Over time, will sub-Saharan African descendents mirror the achievements of African Americans or set a new trend? Does the performance of one black group influence that of another, for example doing well in school, work, and other social arenas?

A recent study by Logan [7] highlights the diversity of black groups in America. Logan [7, page 49] asserts that "new black groups amount to 20 per cent more of the black population". This statement reveals that one-fifth of the black population in the USA is from a foreign-born group from the Caribbean and African countries. In fact, "the number of black Americans born in sub-Saharan Africa nearly tripled during the 1990s. The number identifying a Caribbean ancestry increased by over 60 per cent" [7, page 49]. With varied migration stories, in particular, the mostly voluntary migration to and within the United States of Caribbean and African immigrants, the ways in which foreign-born black groups acculturate and integrate may differ from those ways of American-born blacks.

It still holds true that those prepared and able to migrate will and do so. Whether the migration occurred internally within Africa's prospering nations or abroad to the USA, voluntary migrants tend to accumulate human capital, especially in terms of higher education degrees and are seeking to put this capital to use as soon as possible. Africa still sends more immigrants than refugees and therefore many foreign-born blacks entering the USA from Africa are highly skilled and motivated [8]. According to Logan [7] the social and economic profiles for Africans is above that of African Americans, which means they are employed in higher paying occupations, obtain higher education degrees, and for some cases their skills have transferred over to the American system successfully.

Gordon [9] makes the assertion that black immigrants are aware of the racial divide in America but are more interested in the opportunities present there. The absence of perhaps a direct biological connection and shared history in America complicates the possibility of a shared community and experience with American-born blacks. Foreign-born blacks may not identify with American-born blacks simply because of their shared phenotype. Gordon [9] goes on to say there is no real "African American" rather there exist this insider/outsider ongoing debate about Africans in America that revolves around issues of class versus social status [9, page 89]. The African American link to Africa may be biological and genealogical, however, is not rooted securely 
in African culture [9]. Arguably "most African Americans live through the cultures created in, that is, indigenous to, the New World" [9, page 78]. Essentially the myth of a black community is demystified when examining closely the varied migration stories of black groups in America.Waters [10] explores the visibility and invisibility of black groups, particularly the Caribbean immigrants living on the East Coast of the United States. Waters uses transnationalism and Diaspora culture to explain the experiences of recent immigrants. Again, the year 1990 was singled out as an important year signifying the increase in foreign-born black populations on the East Coast and other coasts as well. Waters [10] asserts that "race serves as a master status defining the person to others" [10, page 5]. Therefore, the identity of these new black immigrants could self-identify as Caribbean and in this study sub-Saharan African, but identity is not only self-identified it is also imposed upon by others, outsiders that would see these black groups as being the same as American-born blacks. This reality posits a dilemma for foreign-born black groups that may not perceive the accomplishments of American-born blacks in a favorable way. Waters [10] then asserts that something happens in response to this automatic grouping: immigrants remain immigrant or ethnic identified, which eases economic and social incorporation into the USA. However, there are two underlying assumptions, one being that those that resist becoming American succeed and the other assumption is those who lose their immigrant ethnic distinctiveness become downwardly mobile [10]. Although identity for any group is layered, there is an added complexity to distinguishing black groups from one another.

There is a common and historically rooted assumption that there is a racial disadvantage for being black or perceived as black within USA society. Although some foreign-born black groups are aware of racial tension between black and white native-born groups, they may feel that they are outside of this debate or share the negative stereotypes of the dominant white culture toward native-born blacks. Thus, the research findings from the qualitative interviews reveal there is sometimes a gendered and generational element to self-identity, and this determines how one may deal with being perceived as a native-born black or African American. For example, in my study William, a newly arriving Kenyan man feels he cannot relate to the black and white racial divide. Hawa, a newly arriving Somali woman, says that after learning the history of race in the USA, she is proud to be perceived as African American and ethnically identifies herself only when asked by an outsider. Naima, a 1.5 generation Ethiopian woman, believes she has a dual identity and has learned to deal with assumptions that she is African America, perhaps because she feels she is as much American as she is Ethiopian.

2.2. African Children in the USA. This section discusses specifically the case of African children growing up in the USA as a whole. In particular, it sheds light on how these children adjust to life in the USA, especially with becoming acculturated and integrated into the education system, language difficulties, and parental pressures to succeed.
Shabaya [11] explores the adjustment conditions for African children in the USA. The experience for African immigrant children may vary significantly to the experience of other foreign-born groups because of the language component. With the rise in immigration from African countries, African immigrant children will experience difficultly with acculturation and integration as they will be socialised within the American education system.

Adapting to a new country provides challenges to all immigrant groups. Shabaya [11] observes that "the growing number of immigrant children from the developing countries has raised several issues, some of which revolve around how well these people adapt into their new society" [11, page 257]. In this particular study, she is determined to highlight the added obstacles faced by African immigrant children growing up in a land foreign to their parents and potentially intimidating to the whole family unit. For example, "as they [immigrant children] adjust to a new life, new school, new language, and a new culture, immigrant children clearly face unique challenges" [11, pages 257 8]. These challenges include difficulty with speaking and understanding the English language and the acculturation differences between foreign-born children growing up in America and having foreign-born parents trying to adjust to a structural society unlike the societies left behind.

Obeng [12] argues that cultural differences put immigrants at risk for hindered adaptation and integration. Her study revealed that many African parents have high expectations for their families, especially their children usually referring to high-paying jobs in the future. One set of parents reported their child was a victim of racism and they went on to explain that their son was picked out for being a troublemaker without any proof in an all white school [12]. These instances can provide families with different views on race than the one they held upon their arrival to the USA. Meaning if their child did experience racism, they may start to see themselves and the opportunities of their children in a more negative way.

Another concern of the parents interviewed by Obeng [12] was cultural alienation and cultural crossing of their children. Some were concerned that their children would become too "Americanised" and forget about where they came from or worse, forget where their parents come from. Other parents were less concerned and "for the few parents who felt there was no cause for concern, their hope was based on the assumption that the children will be able to adjust to the African culture upon return without any difficulty whatsoever and that initial blunders upon arrival would be viewed as normal given that their being away in the United States." [12, page 255]. Their worries about cultural differences were outweighed by their overarching concern about what they perceived to be a beneficial education system, one in which they hope their children will excel.

\section{Generational Outcomes and Racial Ethnic Identity Formation}

In terms of competing identities, racial ethnic identification is central to the process of incorporation in the USA. Race 
plays a major role in determining life chances and social position [13]. Furthermore, "the intermediate categories are defined not only by skin color, but also socioeconomic status and cultural elements" [13, page 225], [14-17]. Waters [18] through her research shows that for immigrants of color, their ethnic choices are restricted and often time racial labels are imposed upon black immigrants leaving them to be grouped in with African Americans. Similar to Caribbean and Dominican immigrants, sub-Saharan African immigrants may decide to reject the black/white dichotomy and highlight their differences through language, dress, and other cultural markers $[13,19]$. Research suggests that over time these distinctions for racial and ethnic identity fade and the experiences, acceptance, and rejection from mainstream society cause many black immigrants to accept and even embrace their racial identity. For some that realise that identity can be fluid, forever changing and evolving and in their control, they assert their ethnic pride politically and by staying connected to their respective ethnic communities in the USA and abroad [20].

The emerging research highlighting the diversity in racial ethnic identity tends to focus on black-white mixed race couples and their children because they fall on the extreme ends of America's racial hierarchy, whites being on top and blacks being on the bottom [21-23]. As stated before skin color is a great predictor of how the outside world classifies a person racially. Rockquemore and Laszloffy state, "the construction of racial identity is tied to one's physical traits" [21, page 121]. Assuming this is true, biracial children with darker skin tones will automatically be classified as black or African American, whereas biracial children with lighter skin tones their racial identity may be more ambiguous. Applying this logic to sub-Saharan African immigrants, depending on the region of Africa, skin tone may vary as will hair texture and facial features; majority will have brown to black skin and be arriving from predominantly black populated places. Their battle in the USA, similar to mixed race black-white children, will be to convince others of their dual identities either racial or ethnic.

Newly arriving sub-Saharan Africans may not be fully aware of what racial discrimination looks like or how to recognise when it happens. Racial discrimination is experienced in many ways. The literature that explores strategies used by African American adolescents and their parents to cope with perceived discrimination sheds light on the relation of racial identity and racial socialization $[24,25]$. This research suggests that as sub-Saharan Africans and other black immigrant groups become socialised in the USA they too will be exposed to and perhaps begin to internalise the negative stereotypes, messages, and images of black people and culture [24]. The exposure to the realities experienced by portions of the African American community in the USA may bridge the gap between the ethnic black groups sooner than later. In Scott's [24] and Noh et al. [26] study revealed that perceived discrimination and discrimination distress were highly related indicating that the more racially aware a person became about racial group placement they had greater perceived discrimination in everyday interactions. Gender was also significant in that "specifically, male participants indicated race was significantly more central to their self-conceptions and identities than did their female counterparts" [24, page 528]. This finding is also supported in Waters [10] research and others who see differences in discrimination experiences among black immigrant and native born and the barrier it may cause in obtaining education and employment across gender lines.

Discovering self and identity construction is not up to the individual alone. Identity construction is as much an internal as it is an external process. As sub-Saharan Africans continue to migrate to the USA and remain in the USA semipermanently or permanently there will be an increase in the number of American-born African children here. Previous research suggests that these children will integrate into society similar to the racial group they are associated with, African Americans [14, 25, 27]. Robinson and Biran [25] highlight theories that may hinder the successful assimilation of American-born African children given that these situations outlined currently prohibit the progress of African American children. The theories include the victim-blame approach, the cultural difference approach, the cultural deficiency approach, and the social approach [25]. Briefly, the victim-blame approach refers to the lack of skills needed for academic success, personality deficits to overcome emotional scar, and motivational deficits. The cultural deficiency approach "suggests that maladaptive and inappropriate behaviors and attitudes acquired from the impoverished backgrounds of African Americans conflict with the attitude and behaviors that are needed to excel in school" [25, page 48]. The social structural approach posits that teachers and administrators in many school systems across the USA hold negative stereotypes of African Americans and relate to the students in ways that signal to the child society assumes you are not going to succeed. Given that these theories hold true, African-born American children will need a buffer that can be acquired through the knowledge of these situations, history of racial relations in the USA, and positive affirmation for continued success from adolescents to adulthood in all sectors of their lives [2225,27 .

\section{Methodology}

For this study, qualitative data are collected through structured interviews, focus groups, and a survey questionnaire. This geographical fieldwork research took place over the course of eight months starting in October 2009 and ending in May 2010. There was a structured focus group containing 6 people, the online distribution of a survey questionnaire containing six open-ended questions, and participant observation at African Student Associations meetings as well as African cultural events and festivities. Focus groups are useful in that they are a "form of group interview that capitalises on communication between research participants in order to generate data... focus groups explicitly use group interaction as part of the method" [28, page 299]. At times I could gain clarity on the views of people through group interaction. Conversations also took unexpected turns in new related and interesting directions. Focus groups are also 
good for insensitive topics like racial ethnic identity [29]. In my focus group findings, I observed that "sometimes group participants could help to translate for each other" [28, page 301]. My focus groups sessions led to follow-up one-one interviews.

Study participants were first recruited at a university in southern California. An e-mail of my project description was sent to all enrolled students with matching criteria: African American or black and over the age of 18 years. From this e-mail students could check their eligibility by answering a short questionnaire consisting of six questions and the call for participants (See Appendix B). There were 30 eligible volunteers selected for this study, and six participants were used to conduct focus groups.

The data are drawn from a random set. Although the student population researched was a convenient sample, I was able to utilise the university's current enrollment to send a call for participants through their campus mail, the population still remains substantially legitimate. Results from this study may be viewed as biased because they depict one subpopulation of African immigrants and perhaps not refugees, although many participants are children of political refugees and discussed these experiences heavily in the interviewing process. This selected group of participants from the university is highly educated and skilled and is comparable to USA Census data for African education achievements in the year 2000. Participants range in age from 18-32 years. Their ethnicities are representative of subSaharan African ancestry and countries including Botswana, Democratic Republic of Congo formerly known as Zaire, Eritrea, Ethiopia, Ghana, Kenya, Liberia, Nigeria, and Somalia. The most populous and representative of the sample were individuals from Eritrea, Ethiopia, and Nigeria. Overall, the individuals have varying times of arrival. I purposefully divided these times into three categories: newly arriving/1st generation, 1.5 generation, and 2nd generation (Following the classification used in Portes and Rumbaut [14] Immigrant America, Berkeley: University of California Press.). During the interview, participants were asked questions about: their plans to stay in the USA or return to Africa; their experiences with discrimination (racial or immigrant status), identity formation; how they or their families give back to Africa when in the USA (for e.g., sending remittances).

All interviews and focus group sessions were fully transcribed and were assessed by participants' responses divided into three categories: newly arriving/1st generation, 1.5 generation, and 2 nd generation. They were divided across generation to track differences among these divisions, if any at all, on how they respond to the posed questions. Dividing the respondents into these categories strengthened the analyses on the assessment of differences for views on education, identity, remittances, returning to Africa, and the experiences of discrimination (racial versus length of stay in the USA). Length of stay refers to time in the USA and also speaks to the differences of experiences for newly arriving immigrants in particular their legal status and familiarity with the English language. There is a heavily female respondent pool, which may be attributed to my identity as an African American female scholar that drew participants with the same characteristics. In addition, there is an increase in African female immigration and a higher black female enrollment in colleges and universities across the USA when compared to their male counterparts [30].

Valuable details that can only be garnered through indepth interviews with a sample of the intended population provide insightful results. These individual testimonies provide insight into the daily lives, culture, perceptions, and attitudes of the people being studied. Obeng asserts "using this research method will help [me] to refrain from imposing [my] ideas on the respondents" [12, page 249]. This method allows for the use of the interviewee's voice, which adds an in-depth understanding of their individual experiences.

4.1. Testing the Research Objectives. Having established the issues of adaptation, of identity, and relative success with integration of sub-Saharan Africans, now I will turn to examining the motivation to move to the USA and their socialization in a new country by using the following research objections: to (a) explore the complexities of racial ethnic identity formation, (b) to assess generational outcomes as they pertain to the sub-Saharan African population in the USA, and (c) to evaluate the role of gender in terms of education outcomes and integration. To explore these inquiries further, I conducted an ethnographic study that took place in Los Angeles, California and Seattle, and Washington. The findings from in-depth interviews, focus group sessions, and participant observation at African student associations, community events, and local festivities were used to reveal key insights into sub-Saharan Africans in four areas: (1) how well they are doing in the USA, (2) their interactions with community, (3) identity formation, and (4) choice to stay in the USA or return to respective African country of origin. During the month of November in 2009, I recruited thirty eligible participants to join focus groups or one-onone interviews with me. The focus group sessions ranged between 45 minutes to 75 minutes. The in-depth interviews ranged from 20 minutes to 90 minutes.

\section{Discussion of Focus Group Findings}

5.1. Findings on Identity. The first focus group session had six participants 2 males and four females, and they were all students. Interestingly, two groups of the participants shared similar ethnic backgrounds. One female is half African American and half Congolese (Amy), two females were Nigerian American, and one female is second generation Eritrean. One male is half African American and half Nigerian (James) and the other is a newly arriving Kenyan. Many of these respondents identified as African American because they were born in the USA and felt they could relate to the experiences of this racial group more than their African ethnic heritage. For example, some of respondents felt less attached to their African ethnic groups because they do not speak Yoruba or Lingala, but each wanted to learn their respective languages at some point in their life. I'll highlight the findings from the two respondents, Amy and James, who were half African American and half African here. 
Amy says

"I kind of want to learn to speak Lingala and French, just because that side of my family speaks French and Lingala."

She is speaking of the Congolese side. The male respondent echoes a similar sentiment by saying,

"Same here. I'm more interested in learning Yoruba."

She goes onto explain why,

"I think it's because I'm not fully Congolese. And I've had that; I've had that response before-being called American in a derogatory way. "You're not African. You're American" when interacting with other Congolese people, and you know other Africans."

The rejection received from this language barrier led her to want to deny that part of her identity. She felt hurt when being confronted with not knowing her father's language proficiently. She explains

"I used to say like just strictly African American, but then I felt like I was denying my father. So now I say African-African American. I don't know really if that makes sense."

It does, identity is layered and complex and being African American and African proved to be at times confusing and isolating because of the perceived difference between foreignborn and native-born black groups. Growing up, the male said

"I don't really have_- probably_-the same experience, because most of the students who have a dual, like both of their parents were from like Africa... So it's just kind of for me a little different. My last name is, my father's."

Having an African last name gave him a sense of pride, but he also felt unsure of that part of his identity. In terms of their shared chosen field of study, African American studies, they expressed wanting to research and improve situations in the African American community, which also showed their affinity to that group.

During this session, it became clear that power and especially gender dynamics were at play which is apparent through response to questions asked and personality differences. Most of the time the male respondent would agree with the female respondent without offering up his own opinion. Neither participant interrupted and respected each other's turn to respond to the questions asked. Given their ethnic background, they also had similar responses to questions related to maintaining a relationship to Africa. For example, when asked if they planned to stay in the USA or return to Africa (the DR of Congo or Nigeria, resp.), both replied that they would stay in the USA because they knew very little of Africa and could never live there, only visit.
Yet, they also both expressed feeling uncomfortable around African Americans or Congolese and Nigerians because they essentially are not one or the other. This conflict is evident in their experiences growing up and trying to fit in at school. No respondent felt very comfortable joining African student associations. Amy responds

I think it's important-theoretically it's important, but I don't think I would feel comfortable connecting with Congolese people here [school], because I feel I'd be seen as American and not Congolese. So I don't really seek out those opportunities to be surrounded by Congolese people.

James seemed uncomfortable with some aspect of his dual identity and more comfortable with other aspects like his last name. He says

When I was younger-I still do... I'm proud that I do have like, like a non-, I guess you can say like a non-British last name or whatever, and I kind of like know where like my name is from and stuff. In high school and middle school I used to always like that fact even though it's long and sometimes kids would try to make fun of it. It was still important to me that like it wasn't given to me or given to my ancestors by slavesyou know slave owners. I've always liked that fact. That I can trace my roots or at least half of my roots back to somewhere directly and I think that was like important.

Amy feels differently and says

I had like the exact opposite experience. I went to an all white school, and I hated my last name. . I hated it, because it-you know people always made fun of it and ask me these ignorant question about my father like does he ride elephants to work and all this crazy stuff. So for a while, I was like man I wish I had Smith as my last name until I got into college and started learning about African history, got into AfroStudies. And now that I'm like proud of my last name, [it's] because I know the history behind it.

\subsection{Findings on Adjustment and Perceived Discrimination.} In this section I will focus more the on the testimonies of two second generation Nigerian women. The dynamics that played out here are telling of their parents' adjustment and continued relationship to Nigeria and also their own ability to continue this relationship. The first respondent, a 28 -yearold woman, grew up in the U.S. but understands and speaks her parents' native tongue. She frequently visits Nigeria and attends Nigeria-related events in Los Angeles on an annual basis. She is proud of her ancestry and owes a lot of this pride to her parents. The second respondent, a 32-year-old woman, grew up in a household where her parents were adamant 
about sustaining ties to Nigeria, but she chose a different path of adjustment and integration compared to the first respondent. The second respondent never felt "Nigerian" enough because she could not speak the language and felt awkward at Nigeria-related festivities. She created her own identity, one in which she is proud of but hardly consists of or is reminiscent of Nigerian ancestry and cultural heritage. Both women were proud of their ethnic group and ancestry lineage, but chose to celebrate this pride in different ways, one showed more internal pride while the other is external in her expressions of pride, most obvious in dress.

These respondents agreed that discrimination against black groups in the USA still exists, and that black males were targeted more than black women. These two women also felt black women were stronger than black men in terms of combating negative stereotypes and obstacles to succeed. The first respondent states

I've kind of thought about it to a certain degree. Maybe it's just that tension as far as the stamina, the dedication that many women may, you know, exude in comparison to male counterparts. Just the fact that maybe women as far as educationally may be more inclined to-like, okay, as opposed to men who may do something quicker. Like, okay, let me just hop right into something like business or let me try my luck with whatever it is as far as, whereas women may be more cautious and kind of go that straightforward route in comparison.

Both of these women were graduate students pursuing higher education science degrees.

\subsection{Findings on Generational Differences and Ethnic Identity} and Pride. The Eritrean second generation female and a newly arriving Kenyan male shed light on generational outcomes in the USA in terms of racial ethnic identity formation. The female respondents held a more dominant presence than the males. This observation could be related to the fact that English is their first language, although some were bilingual, for example the Eritrean respondent also spoke Tigrinya. The Kenyan male arrived roughly six years prior in 2004 and spoke softly and made many grammatical mistakes but is clearly educated and articulate. He is 38 years old, the oldest of the focus group and interview respondents, and had plans to return upon the completion of his advance degree in African Studies. The Eritrean woman plans to stay in the USA, but insists on spreading knowledge about her culture and people anyway she can. She is actively involved in school and community cultural organizations. In fact, her parents started the first Eritrean Association in Orange County, California in the 1970s and 80s, when they first immigrated. She feels as though she can better help Eritrea while in the USA because of the educational opportunities and possibilities for political mobilization. The interaction between the two respondents is minimal but respectful. Both, however, identified more with their country of origin or ethnic group than African American because of pride, length of time in the USA, and parental influence and sustained connection to Africa.

The previously discussed account of six focus group participants is a snapshot of the diversity within and across sub-Saharan Africans in the USA. In Tables 1 and 2 (see Appendix A), I display the interview and focus group session sample data. The respondents ranged in age between 17 and 38 years old. The average age is 23 years. There were 22 female and 8 male respondents. There were more respondents with Nigerian, Ethiopian, and Eritrean ancestry than any other ancestry group. Most of the respondents were second generation, but there is also a substantial amount of newly arriving immigrants from Kenya and The Democratic Republic of Congo. There is one respondent from Botswana. Four out of eight males and 21 out of 22 females said they experienced discrimination, either due to their racial ethnic identity or immigrant status. Seven men and 20 women send remittances to their respective countries in Africa. Note that some of these remittances may have been sent by the respondents' parents. Six of the female respondents identified as African American, five identified with their African ethnic group, and 11 identified with both. Two of the male respondents identified as African American, five identified with their African ethnic group and one identified as both. There were 15 female respondents and one male respondent planning to stay in the USA. Six out of seven foreign-born males and five out of seven female respondents had plans to return to their respective countries in Africa. While two out of seven females and one out of seven expatriates plan to return to Africa, maybe not to live but construct a life that involves migrating back and forth. Twenty one out of 22 female and seven out of eight male respondents were actively involved in cultural organizations, either on or off campus.

\section{Discussion of Interview Findings}

6.1. Identity Formation. To access how one racially or ethnically identifies, respondents were asked to self-report on their identity. Using these self-reports, it is clear that how respondents chose to identify is more complex than skin tone, arrival times, and citizenship. In fact, identity had more to do with family relations, participation, and connection with family members in Africa, strong ethnicidentified parents, and country-specific politics.

American-born Africans or second generation Africans tended to identify as African American or both African and American, for example Nigerian and American. For the respondents arriving to the USA after the age of seven, they tended to identify more with their country of origin, even though they hardly remembered Africa. They learned the customs and language through daily interactions with their parents and members of the same ethnic group, usually at cultural festivities and events. Newly arriving African immigrants tended to identify as whatever African country they originate from and did not closely identify with American culture. When I asked the respondents: do you most identify with your national origin, country of origin, or as an African American? Please explain your answer. 
TABLE 1: Demographic aspects of migrants.

\begin{tabular}{|c|c|c|c|c|}
\hline Participants & Classification & Sex & Age & Type \\
\hline \multicolumn{5}{|l|}{ Country of origin } \\
\hline Botswana & Newly arriving & $\mathrm{M}$ & 31 & Interview \\
\hline Nigeria & 2nd generation & $\mathrm{M}$ & 22 & Focus group \\
\hline Nigeria & Newly arriving & $\mathrm{M}$ & $30 \mathrm{~s}$ & Interview \\
\hline Kenya & Newly arriving & $\mathrm{M}$ & 38 & Focus group \\
\hline Ethiopia & Newly arriving & $\mathrm{M}$ & 20 & Interview \\
\hline Ethiopia & Newly arriving & $\mathrm{M}$ & 26 & Interview \\
\hline Ethiopia & 2nd generation & $\mathrm{M}$ & 33 & Interview \\
\hline Ghana & Newly arriving & $\mathrm{M}$ & 27 & Interview \\
\hline Liberia & 1.5 generation & $\mathrm{F}$ & 22 & Interview \\
\hline Congo & 2nd generation & $\mathrm{F}$ & 24 & Focus group \\
\hline Congo & Newly arriving & $\mathrm{F}$ & 19 & Interview \\
\hline Nigeria & Newly arriving & $\mathrm{F}$ & 20 & Interview \\
\hline Nigeria & 2nd generation & $\mathrm{F}$ & 27 & Interview \\
\hline Nigeria & 2nd generation & $\mathrm{F}$ & 28 & Focus group \\
\hline Nigeria & 2nd generation & $\mathrm{F}$ & 32 & Focus group \\
\hline Nigeria & 2nd generation & $\mathrm{F}$ & 31 & Interview \\
\hline Ghana & 2nd generation & F & 26 & Interview \\
\hline Ghana & 2nd generation & $\mathrm{F}$ & $20 \mathrm{~s}$ & Interview \\
\hline Eritrea & 2nd generation & $\mathrm{F}$ & 19 & Interview \\
\hline Eritrea & 2nd generation & $\mathrm{F}$ & 22 & Focus group \\
\hline Eritrea & 1.5 generation & $\mathrm{F}$ & 25 & Interview \\
\hline Eritrea & 2nd generation & $\mathrm{F}$ & 25 & Interview \\
\hline Eritrea & Newly arriving & $\mathrm{F}$ & 24 & Interview \\
\hline Ethiopia & 2nd generation & $\mathrm{F}$ & 26 & Interview \\
\hline Ethiopia & 1.5 generation & $\mathrm{F}$ & 25 & Interview \\
\hline NA (Afro-Caribbean) & Newly arriving & $\mathrm{F}$ & 28 & Interview \\
\hline Somali & Newly arriving & $\mathrm{F}$ & 24 & Interview \\
\hline Oromo & 1.5 generation & $\mathrm{F}$ & 26 & Interview \\
\hline Kenya & Newly arriving & $\mathrm{F}$ & 24 & Interview \\
\hline Kenya & Newly arriving & $\mathrm{F}$ & 17 & Interview \\
\hline
\end{tabular}

Then, do you believe there is a downside to identifying with one or the other? Please explain. And, is there an upside to identifying with one or the other? Please explain. Their responses varied depending on time of arrival and how the outside world views them and labels them. Here are a few examples:

Semhar replies

I mostly identify as an Eritrean, not so much as an American. But I feel like that's because when I moved here, I was already like eighteen. I was seventeen, going on eighteen, so most of my life was in Africa, and that's how I was raised, so my norms were totally different from the American norms over here.

Semhar also discussed how she does not always know how to identify, especially with regard to citizenship. She goes on to explain

There is some down sides, but it's not-it's mostly identifying yourself as an American towards the Eritrean community, but not viceversa. You can be an Eritrean in an American community and there's not going to be a down side, but when you identify yourself as an American in the Eritrean community, then it's kind of like you're telling them you don't value their cultural-the Eritrean culture.

Clearly, what citizenship means for some varies by ethnic communities in the USA. Semhar believes her identity is threefold. She feels she is Eritrean in terms of her cultural identity, American in terms of her school activities and involvement, and African American when filling out forms.

Naima answers simply

"I think half-half."

She further explained that having a liberal education has influenced the perspective by which she views the world, but that her parents played a major role in forming her identity and perspective as well. Naima says 
Table 2: Adjustment in the USA and ties to Africa.

\begin{tabular}{|c|c|c|}
\hline Selected variables & Male & Female \\
\hline \multicolumn{3}{|l|}{ Country of origin } \\
\hline Botswana & 1 & 0 \\
\hline DR of Congo & 0 & 2 \\
\hline Ethiopia & 3 & 2 \\
\hline Eritrea & 0 & 5 \\
\hline Ghana & 1 & 2 \\
\hline Kenya & 1 & 2 \\
\hline Nigeria & 2 & 5 \\
\hline Oromo & 0 & 1 \\
\hline Somalia & 0 & 1 \\
\hline \multicolumn{3}{|l|}{ Generation } \\
\hline Newly arriving & 6 & 6 \\
\hline 1.5 & 0 & 4 \\
\hline Second & 2 & 11 \\
\hline \multicolumn{3}{|l|}{ Plan to return } \\
\hline Ethnic origin & 6 out of 7 & 5 out of 7 \\
\hline Expatriate & 1 out of 7 & 2 out of 7 \\
\hline Stay in the USA & 1 & 15 \\
\hline \multicolumn{3}{|l|}{ Identity } \\
\hline African American & 2 & 6 \\
\hline Country of origin & 5 & 5 \\
\hline Both & 1 & 11 \\
\hline $\begin{array}{l}\text { Experienced } \\
\text { Discrimination (racial } \\
\text { or immigrant status) }\end{array}$ & 4 out of 8 & 21 out of 22 \\
\hline $\begin{array}{l}\text { Involved in cultural } \\
\text { organizations }\end{array}$ & 7 out of 8 & 21 out of 22 \\
\hline \multicolumn{3}{|l|}{ Send remittances } \\
\hline Yes (includes parents) & 7 & 20 \\
\hline No & 1 & 2 \\
\hline $\mathrm{N}$ (sample size) & 8 & 22 \\
\hline
\end{tabular}

I think there's a conflict. That's the hardest part about identifying with one or the other is that even if you identify with one more than the other, the other one doesn't just disappear? It's still somewhere in there, but it has a less powerful role. And so that's what I've meant before by struggle is that these things are always there, but depending on what. Like in school, maybe my American side might be more, you know, dominant, but in other areas like different relationships I'm probably more traditional.

These different relationships she refers to are familial or with friends with similar ethnic backgrounds. Here Naima discusses the conflict to choosing and negotiating her identity. She believes that most people just see her as a person of color, a black person, and mostly as a black woman.

Jene replies with
"I think it's a dual thing for me. It's a dual identity. Because it's like, I always say first I'm a Liberian woman, because that's what I am."

She is proud of her ancestry and has a belief similar to Naima, in that first and foremost, she is seen as another black person. Jene can also recognise and appreciate when others acknowledge her ethnic background.

Ashley says

I mostly identify with African-Americans. I am aware fully like my culture but as I operate in the world, like how I am perceived, I don't have a control over; it seems that like it's always been African-American. And because I was the last, youngest person in my family and I was like raised more all the way in America, my experiences tend to reflect' similarly with African American experiences.

Ashley identifies more with African Americans because she was born in the USA and has been socialised to identify racially and take notice of situations and circumstances that reflect a racial undertone and positioning.

Both William and Hawa believe identity formation depends on where you are when being asked. For instance, William identifies either as Kenyan or East African and not African American because he was not born in the USA He says

"And when I'm in Kenya again, the thing is the same. I will have my own ethnic identity that I feel comfortable with so it just depends on where you are."

\section{Hawa explains}

The identity thing used to give me a little issue when I came here to the United States, because I hadn't understood what race was when I was in an African city because I always get confused with being black and American, because to me it meant the same thing. But I realise that because in America there is such a thing as race; whereas if you go to where I'm from, Somalia, there's no such thing as race [but there is tribalism]. Everybody knows you're black. Nobody asks you that. Even in Saudi Arabia there's no such thing as race. There's always ethnicity, so you always associate where your origin was. So at first I associated myself as a Somali-American, and people asked me my broader clarification, and I say African-American. And, yes, I am AfricanAmerican.

It took Hawa a while to understand the "right" racial identity classification when in the USA, but now she is comfortable with a few labels that she feels capture her unique history, culture, and migration experiences.

Respondents were then asked to report on other basic questions like knowledge and speaking ability of other 
African languages or dialects and about their current educational pursuits. Many of the respondents spoke or understood two languages, usually English and their native country's official language or less spoken dialects. This piece of information supports the literature that African children are arriving with knowledge of various languages and dialects.

The respondents were then asked whether or not they felt there was an upside or downside to identifying with their country of origin or as an African American? Semhar and many other respondents commented on general assumptions made about their ethnicity and origin. She explains

"I do get reactions because they look at me," they say, "Okay, you're probably black, AfricanAmerican,"

she goes on to explain how she has to tell people she is from Kenya and tends to receive a surprise reaction. She further insisted these same people knew little about the African continent, but after their conversation wanted to know more.

Jene says there are some downsides to identifying with her African ancestry. She explains

"People are very ignorant about African culture. They lump it all together... People say ignorant things like speak "African" and, or like they think like you know they're [all] still bush people.”

She feels she always has to defend herself and her country to white and black native-born friends. Despite this drawback, she says

"But honestly at the end of the day, I just love being a-just being Black. I'm like, I, we have our ups and downs, but I feel like it's a good thing to be Black. No, no problems with that."

She sees the advantage of identifying with her ethnic group as providing her with a sense of self and that pride goes a long way in helping her to achieve her goals in life.

6.2. Generational Outcomes for Staying in the USA. The questions asked to obtain information on respondents' likelihood of staying permanently or temporarily in the USA provided valuable insight into which of these migrants plan to take part in the return migration of sub-Saharan Africans. Some respondents believed they could do more for the continent of Africa if they stayed in the USA. Given the education and employment related opportunities in the USA, many respondents with plans to return to Africa felt returning before the accumulation of human capital was unacceptable. Political freedom and expression were also seen as an avenue to empower respective Africans nations back home. This section explores how sub-Saharan Africans in the USA stay connected to Africa and how members of this population decide when to stay and if and when to go back.

6.2.1. Staying Connected. The theme and concept of staying connected to Africa came up in reaction to responses from the interview questions, especially those on community and how their cultural attributes have or have not been linked to their success. Many of the respondents felt very passionate about this topic and most insisted they will maintain their connection to Africa in some way. Take for example, Semhar who stated
"So my family's still in Eritrea, and the way we keep communicating, we haven't gone back since we came here, but that's just because we also got our citizenship last year... We always call at least once a month."

For Semhar and her family, retaining communication with family back home is very important. Here are few more examples. Jene says

\begin{abstract}
"I'm connected through my parents really, because I don't have money for the plane ticket. My parents actually moved back to Liberia, so they come back and forth."
\end{abstract}

Her parents are transnational. They moved back to Liberia when they were able to afford a better life there. She feels she is out of touch with the country but stays connected to the Liberian community in Los Angeles. For example, attending an event, July 26th is Independence Day for Liberia.

Ashley remains very connected to Ghana because she is able to travel there all the time. She is different from the others in this regard and probably because she is not burdened by financial setbacks. She has the means to travel and this does not necessarily have anything to do with her having a more emotional attachment, although it might. She explains

Our whole family is very connected to Ghana. My family has like a business there. My mom and dad have a home there, home is there. They definitely send family money to a lot of different family members there. We have a lot of family that's well off, and we have a lot of family that's not. And so there's definitely a financial connection, an economic connection, to Ghana. I think my parents are going to return to live primarily. I'm probably not. I'm going to stay here. I'll probably always visit, but I don't really feel the need to be there.

Many 1.5 and second generation Africans or Africanborn Americans cannot see themselves living in Africa like their parents can. Arica never seems to leave the hearts and minds of these respondents and in many instances, their career goals and future plans involve a relationship to the continent, even if this relationship is not marked by permanent residence.

6.2.2. Remittances. Most of the respondents talked about their parents sending remittances to relatives and owning houses in their countries of origin. Remittances have been shown to help maintain failing economies as well as provide 
political mobilization for disadvantaged communities. The response to questions about continuing remittances led to some interesting findings. Second generation respondents had not thought about continuing to send money if their parents pass away and felt it would only continue so far as there was the family Africa to receive it.

Some of the respondents expressed their excitement to return to or visit Africa. Semhar can hardly wait to visit Eritrea because she has never been. Now that she is in the USA and has citizenship, she can enter and leave the country as she pleases. In the meantime, her family, siblings, and parents sends money to relatives, grandmother, and uncles, back home. The remittances sent back to Africa have allowed many Africans in the USA to establish homes in their origin countries. Naima says

"[there is] money being sent and my parents built a house there, so they have intent to return. [In terms of] visits, we go not every year but we go-I mean, somebody goes every year."

Families like Naima's are constantly developing and strengthening ties to the USA and their respective countries back home by investing emotionally and financially in both places.

6.2.3. Return to Live in Africa or Stay in the USA. Of the twelve respondents that are nearly arrived, eleven of them plan to return to African upon the completion of their advanced degrees. Many of the 1.5 generation plan to stay in the USA, but plan to maintain a relationship to Africa by visiting, contributing skills acquired abroad, and staying connected to family members there through e-mail, letters, and phone calls. The second generation respondents will stay in the USA; however, they expressed interest in traveling to Africa and giving back to the continent somehow, either through their research efforts or supporting initiatives for improvement taking place there. Eighteen out of thirty respondents, of 1.5 and 2 nd generation, had never visited or remembered Africa, nevertheless were committed to maintaining at least familial ties. Although it seems the second generation is losing ties to Africa, the immigrants from this continent are still arriving in record numbers, which is an outcome of push factors such as failed economies in Africa and pull factors in the USA like a relatively more stable economy. Respondents were asked whether they plan to stay in the USA or return to their respective countries in Africa.

\section{Discussion and Overview}

Recent sub-Saharan African migrants are not unlike other black immigrant groups but may differ more so from nonblack immigrants. Africans in the Diaspora construct their own sense of racial and gender identities that affect intergenerational identities. There exist this duality of race and ethnicity by which black immigrant groups must negotiate their identity in daily interactions with nativeborn blacks and nonblacks in the USA. The countries from which this sub-Saharan African population are migrating from have a unique colonial history and in direct result have a social, economic, and political system unlike those in Latin America and Asia. Colonial rule in Africa consisted of, but was not limited to, Spanish, German, English, Portuguese, and French influence. The official languages spoken in each country pale in comparison to the thousands of dialects spoken within countries and across the continent. In addition, the tribal affiliations, cultural differences, and diversity of landscape and people living there further support the level of uniqueness of immigrants arriving from this region of the world.

As immigrants from sub-Saharan Africa continue to migrate to the USA and while some maintain their ties (emotional and financial) to their country of origin, it is clear their presence in the USA will change the concept of what it means to be an immigrant from Africa, given the history of forced migration during the Trans-Atlantic Slave Trade. While some sub-Saharan Africans are arriving with little option to do otherwise, and are here seeking refuge and asylum, the majority arriving chose to migrate. This portion of the population is also interested in obtaining skills and education by any means and without a timeframe, which is evidenced by their permanent residency.

The prolonged presence of sub-Saharan Africans in the USA and settlement has changed and diversified the black population and perhaps the connotation associated with being a black person in the USA. As some of the interview and focus group testimonies revealed, differentiation between black groups is important for some and less for others. Some participants insisted they have a dual identity, and in most cases, identity had more to do with length of time in the USA. The amount of time one lived in the USA and also their family impacted the relationship they had with African Americans and vice versa. Newly arriving and some 1.5 generation sub-Saharan Africans thought it most important to maintain their tribal and ethnic identity because it is more significant to them than their racial identity. Some African Americans may perceive this choice not to racially identify as African American as a rejection, while others understand the solidarity to Africa and connection with origin country, culture, and pride. Some of the short-term outcomes of this for race and ethnic relations in America might be tension between black ethnic groups and increased efforts to display their differences. A long-term, and perhaps optimistic, outcome would be that overtime the black ethnic groups are more united by their differences and appreciative of cultural backgrounds similar but unlike their own.

Permanent residency of sub-Saharan Africans in the USA or the maintaining of a transnational connection to Africa proves to be on the agendas of this study's interviewees. As more enter and eventually integrate, more children will be born to African parents (newly arriving, 1.5, and second generation), and they will represent a larger proportion of the African American racial group. The label "African American" may make more sense and seem fitting to those that critiqued its significance in the 1960s and 1970s. The 
critique being African Americans in the USA had no real connection to Africa from having spent many decades in the USA and the circumstances to the conditions they arrived under. The label to describe black persons born in the USA has gone through many changes and this group was once referred to as "Negro" or as "Colored" people. The new (first generation, 1.5 and second generation) African Americans do and prove to have a continued connection to the continent of Africa.

It has been suggested that the residential and settlement patterns of Africans in the USA follow the same pattern of Latinos. The implications of this are that the discussions around racial and ethnic identities may become further complicated with Latinos being the largest minority group, a title once held by African Americans in this country. Multiple ethnicities make up the Latino population and now a similar situation is occurring for African Americans. Identity politics will no doubt be reshaped by the increasing diversity of immigrants making up two racial groups in the USA. What these layered identities mean for Africa as a whole and the source countries of the immigrants will also be important. These identity transformations may impact the native homelands of the immigrants in both positive and negative ways. In terms of positive outcomes, ethnic groups may hold onto their traditions and strengthen their ties to origin countries through remittances and communication via travel, internet, and phone calls. In terms of negative outcomes, ethnic groups may shed ties to their origin country to become better integrated in the USA adopting a more racial identity and cutting off communication to Africa for future generations.

\section{The Role of Gender and Future Research}

The findings for the female participants, supported by previous research, reveal they felt fewer hindrances to obtaining their education. Male respondents noticed the obvious gender gap in enrollment in higher education institutions and expressed some concern for this inequality. For other minority groups such as African American and Latino populations, this gender gap is also present in their communities. Future research should evaluate the attitudes and experiences of adjustment and integration of minority women, in particular black (native and foreign-born), without their male counterparts represented in similar socioeconomic standings. How does this phenomenon of educating more black women than black men impact other arenas of their lives, for example marriage, cultural practices specific to gender, conceptualizing family structure, and the socioeconomic advancement of one half of a racial group in the USA.

\section{Appendices}

A.

For more details see Tables 1 and 2.

\section{B. Call for Focus Group Participants-Included a Six Open-Ended Questions Online Questionnaire}

Hello,

My name is Natasha Rivers and I am a doctoral candidate in the UCLA Geography Department. My dissertation titled, An Evaluation of Historical and Contemporary subSaharan African Migration to and within the United States, is looking for volunteers to participate in a focus group. If you cannot attend a focus group, and would like to contribute/participate in this study you can complete a questionnaire with similar questions. Ask me for the questionnaire.

B.1. Purpose of the Study. This study is designed to evaluate the migration experience of sub-Saharan African immigrants to and within the US. It will examine the push and pull factors involved with the increased migration of African immigrants to the US, their dispersal once they arrive and how well these groups are performing in areas of education attainment and the labor market. In addition, this study also seeks to explore questions related to the forming of identity in terms of racial categorization and the impacts, if any at all, on performance in terms of education attainment and job market success or failure.

If you can answer yes to any of these questions, you are eligible for this study. Each participant will receive compensation for their participation in the study. Eligible participants may inquire further about their compensation.

B.2. Questions to Check for Eligibility. If You Answer Yes to Any of These Questions You Are Eligible for This Study: Are you or your family from Nigeria, Ethiopia, Kenya, Ghana, Somalia or another sub-Saharan African country not listed?

Would you classify yourself as 1st generation (not born or raised in the US, but live here now), 1.5 generation (not born in the US, but arrived by age 7 ) or 2 nd generation (you were born in the US, but are a direct descendent of one of the above listed African origin groups)?

Are you the first in your family to go to college? Do you believe that the cultural attributes linked to your ethnic background help you to succeed in school or in the labor market?

Do you identify as being an ethnicity other than African American, but identify as black?

Do you speak more than one language, African dialect or language?

B.3. *Who Can Participate?* * Community College, Cal State, UC Undergraduate \& Graduate Students and recent graduates of sub-Saharan African descent and are at least 18 yrs of age.

Your participation will include the completion of a 1.5 to 2 hour focus group. Before we begin the focus group you will receive a consent form to be signed before participating in this study. This study is $100 \%$ confidential and anything said 
during the focus group will in no way be linked back to any individual person.

If you choose to participate, please direct all questions, comments or concerns to my e-mail: riversn@ucla.edu. Make sure to put in the subject line of the e-mail "focus group participant".

Indicate your first and second choice by placing 1st or 2nd next to your desired date in your e-mail reply.

\section{B.4. Available Dates to Attend a Focus Group Session:}

Week 7: November, Monday 9th from 9a-11a or Thursday $5-7 \mathrm{pm}$

Week 8: November, Monday 16th from 9a-11a or Thursday $5-7 \mathrm{pm}$

Week 9: November, Monday 23rd from 9a$11 \mathrm{a}$

Week 10: November, Monday 30th from 9a$11 \mathrm{a}$

Please do not hesitate to ask me questions before, during, or after your participation in the study.

Natasha Rivers, MA

Doctoral Candidate

Geography Department

Attn: Natasha Rivers

1255 Bunched Hall Box 951524

Los Angeles, CA 90095

University of California, Los Angeles

riversn@ucla.edu

Copyright (C) $2009 *$-Natasha Rivers—* All rights reserved.

\section{Disclosure}

Project was approved by the Office for Protection of Research Subjects' Review Board October 23, 2009, Certified Exempt \#09-234A.

\section{References}

[1] A. Terrazas, "African Immigrants in the United States," Migration Policy Institute, 2009, http://www.migrationinformation .org/.

[2] Census Bureau Data, Summary Statistics, 2010, http://www .census.gov.

[3] American Community Survey, http://www.census.gov/acs.

[4] J. A. Arthur, "The new African diaspora in North America: policy implications," in The New African Diaspora in North America, B. K. Takyi and J. A. Arthur, Eds., pp. 287-302, Lexington Books, New York, NY, USA, 2007.

[5] M. Vesely, "Africans in the US-second wave migrants outdo African-Americans," African Business, vol. 38, no. 2, p. 309, 2005.

[6] J. A. Arthur, Invisible Sojourners: African Immigration Diaspora in the United States, Library of Congress, 2000.

[7] J. R. Logan, "Who are the other African Americans? contemporary African and Caribbean immigrants in the U.S," in The other African Americans: Contemporary African and Caribbean immigrants in the United States, W. S. Taylor and S. A. Tuch, Eds., pp. 49-68, Rowman \& Littlefield Publishers, Md, USA, 2007.

[8] Department of Homeland Security, "Immigration Statistics: Table 10: Persons Obtaining Legal Permanent Resident Status by Broad Class of Admission and Region and Country of Birth: Fiscal Year," (XLS, 38 KB), 2009, http://www.dhs.gov/.

[9] L. R. Gordon, "Thinking through identities: black peoples, race labels, and ethnic consciousness," in The Other African Americans: Contemporary African and Caribbean Immigrants in the United States, W. S. Taylor and S. A. Tuch, Eds., pp. 6992, Rowman \& Littlefield Publishers, Md, USA, 2007.

[10] M. C. Waters, Black Identities: West Indian Immigrant Dreams and American Realities, Russell Sage Foundation, 1999.

[11] J. Shabaya, "English language acquisition and some pedagogical issues affecting the adaptation of african children," in The New African Diaspora in North America, K. KonaduAgyemang, B. K. Takyi, and J. A. Arthur, Eds., pp. 257-272, Lexington Books, New York, NY, USA, 2007.

[12] C. S. Obeng, "African immigrants families and the American educational system," in African Minorities in the New World, T. Falola and N. Afolabi, Eds., pp. 247-260, Routledge Publishing, New York, NY, USA, 2008.

[13] J. Itzigsohn and C. Dore-Cabral, "Competing identities? Race, ethnicity and panethnicity among Dominicans in the United States1," Sociological Forum, vol. 15, no. 2, pp. 225-247, 2000.

[14] A. Portes and R. G. Rumbaut, Immigrant America, University of California Press, Berkeley, Calif, USA, 1996.

[15] C. Rodriguez, "Race, culture, and Latino "otherness" in the 1980 Census," Social Science Quarterly, vol. 73, pp. 931-937, 1992.

[16] M. Hughes and B. Hertel, "The significance of color remains: a study of life chance, mate selection, and ethnic consciousness among Black Americans," Social Forces, vol. 68, pp. 1105-1120, 1990.

[17] N. A. Denton and D. S. Massey, "Racial identity among Caribbean Hispanics: the effect of double minority status on residential segregation," American Sociological Review, vol. 54, no. 5, pp. 790-808, 1989.

[18] M. C. Waters, "Ethnic and racial identities of secondgeneration black immigrants in New York City," International Migration Review, vol. 28, no. 4, pp. 795-820, 1994.

[19] K. A. Cerulo, "Identity construction: new issues, new directions," Annual Review of Sociology, vol. 23, pp. 385-409, 1997.

[20] R. A. Jones, "Race and revisability," Journal of Black Studies, vol. 35, no. 5, pp. 612-632, 2005.

[21] K. A. Rockquemore and T. A. Laszloffy, "Multiple realities: a relational narrative approach in therapy with black-white mixed-race clients," Family Relations, vol. 52, no. 2, pp. 119128, 2003.

[22] K. A. Renn, "Understanding the identities of mixed-race college students through a developmental ecology lens," Journal of College Student Development, vol. 44, no. 3, pp. 383403, 2003.

[23] K. A. Renn and K. D. Arnold, "Reconceptualizing research on college student peer culture," Journal of Higher Education, vol. 74, no. 3, pp. 261-291, 2003.

[24] L. D. Scott Jr., "The relation of racial identity and racial socialization to coping with discrimination among African American adolescents," Journal of Black Studies, vol. 33, no. 4, pp. 520-538, 2003. 
[25] J. Robinson and M. Biran, "Discovering self: relationships between African identity and academic achievement," Journal of Black Studies, vol. 37, no. 1, pp. 46-68, 2006.

[26] S. Noh, M. Beiser, V. Kaspar, F. Hou, and J. Rummens, "Perceived racial discrimination, depression, and coping: a study of Southeast Asian refugees in Canada," Journal of Health and Social Behavior, vol. 40, no. 3, pp. 193-207, 1999.

[27] J. E. Benson, "Exploring the racial identities of black immigrants in the United States," Sociological Forum, vol. 21, no. 2, pp. 219-247, 2006.

[28] J. Kitzinger, "Introducing focus groups," British Medical Journal, vol. 311, no. 7000, pp. 299-302, 1995.

[29] G. Creese and E. N. Kambere, "What Colour is Your English?" Canadian Review of Sociology and Anthropology, vol. 40, no. 5, pp. $565-573,2003$.

[30] I. E. A. Yeboah, "Globalization and Ghanaian immigrant trajectories to Cincinnati: who benefits?" in The African Diaspora in the United States and Canada at the Dawn of the 21st Century, J. W. Frazier, J. T. Darden, and N. F. Henry, Eds., pp. 287-306, Global Academic Publishing, Binghamton University, 2009. 


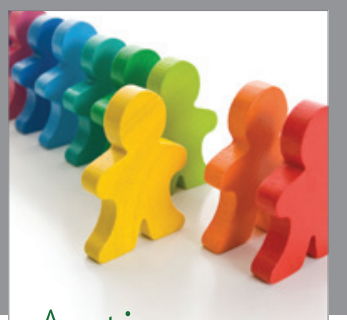

Autism

Research and Treatment
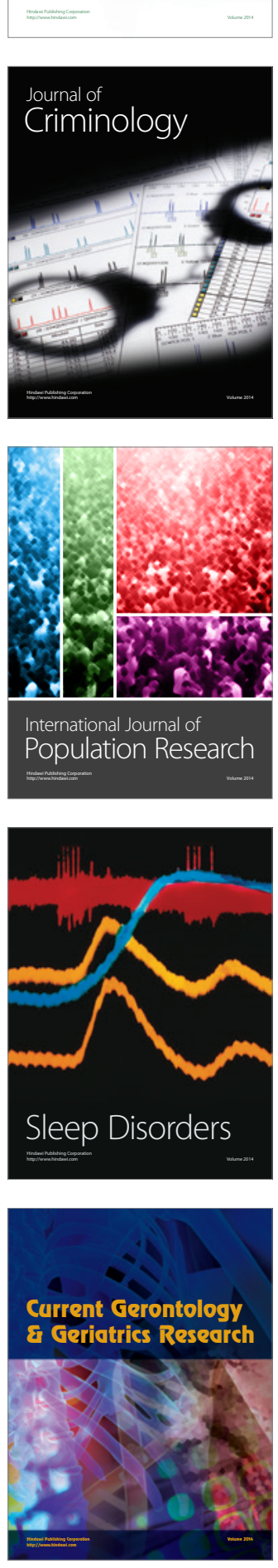
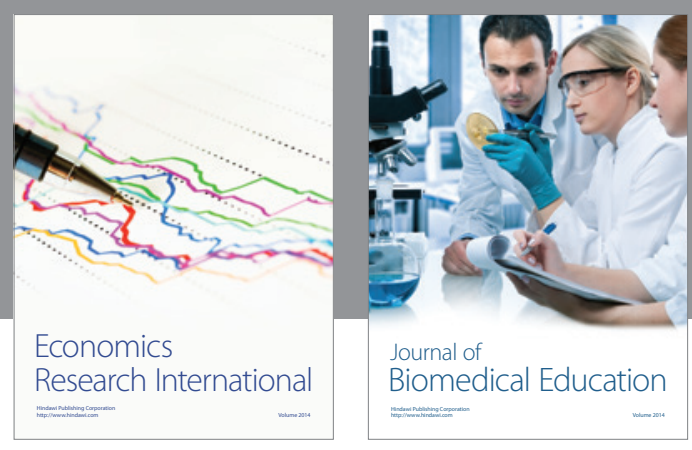

Journal of

Biomedical Education

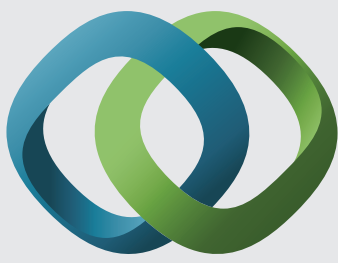

\section{Hindawi}

Submit your manuscripts at

http://www.hindawi.com
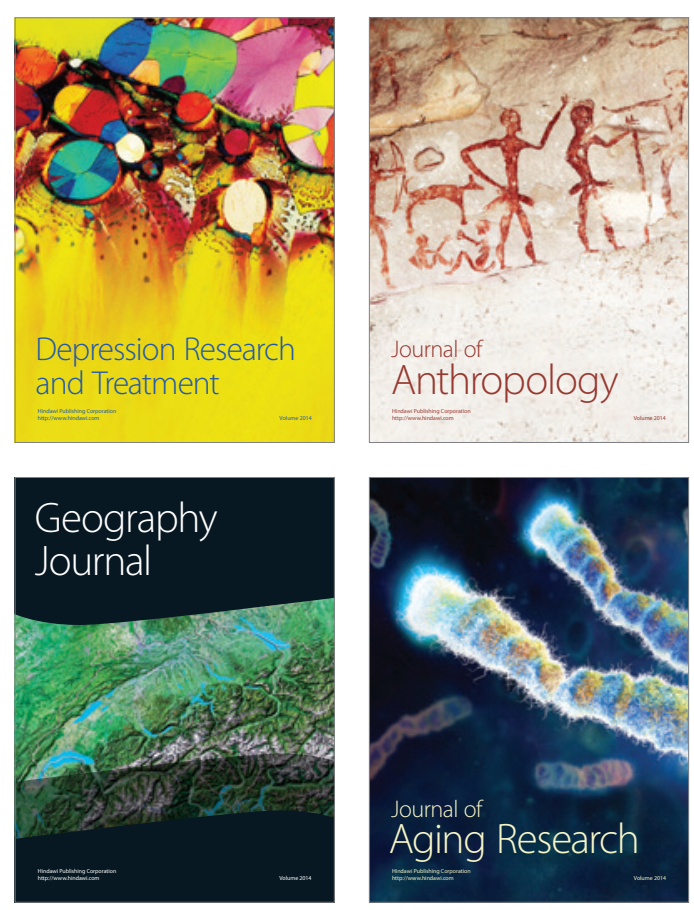

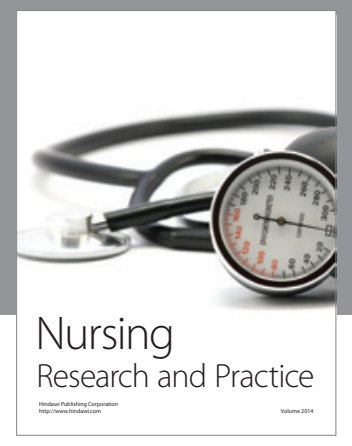

Nursing

Research and Practice

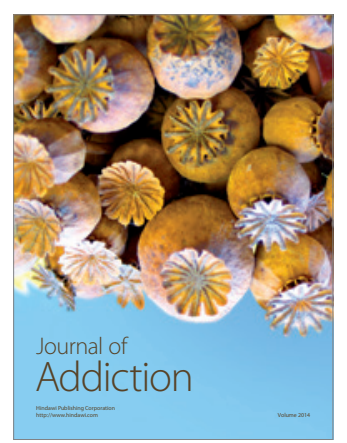

Child Development

Research

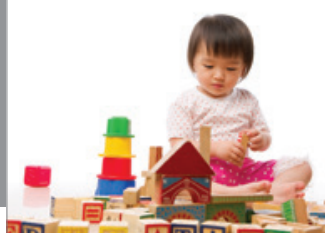

迥
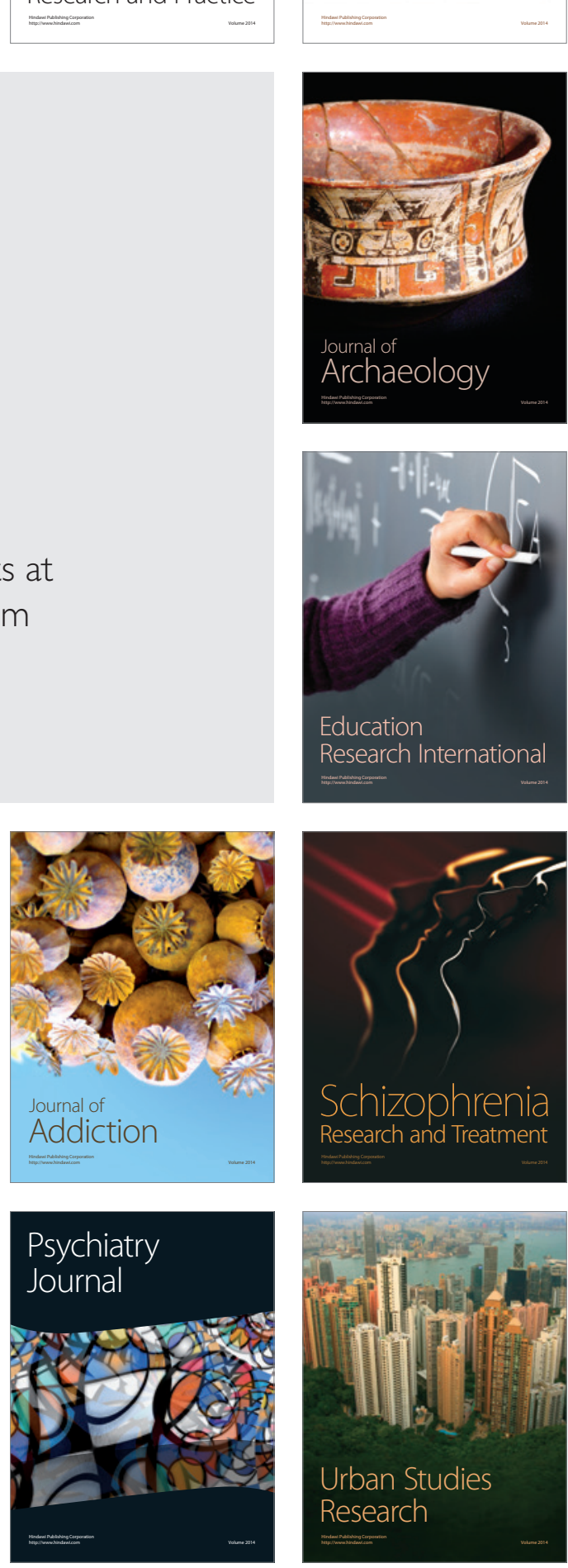